\title{
A Critical Review of Healthcare Human Resource Development: A Saudization Perspective
}

\author{
Fahad Alhazmi \\ King Abdulaziz University, Jeddah, Saudi Arabia \\ Email: fnalhazmi@kau.edu.sa
}

How to cite this paper: Alhazmi, F. (2021) A Critical Review of Healthcare Human Resource Development: A Saudization Perspective. Health, 13, 1496-1510. https://doi.org/10.4236/health.2021.1312107

Received: November 1, 2021

Accepted: December 21, 2021

Published: December 24, 2021

Copyright $\odot 2021$ by author(s) and Scientific Research Publishing Inc. This work is licensed under the Creative Commons Attribution International License (CC BY 4.0).

http://creativecommons.org/licenses/by/4.0/

\begin{abstract}
Saudi Arabia is currently in a transformation phase, which has resulted in a significant demand for healthcare services in the country's healthcare system to provide better healthcare facilities for the fast-growing population and the growing elderly population. The lack of trained healthcare professionals and strong dependence on foreign labour are important aspects for policymakers to address, thus requiring Human Resource Development (HRD) initiatives to provide adequate learning and competence to a huge reserve of healthcare professionals in Saudi Arabia. In this regard, this paper contributes to Saudi Arabian health care by reporting healthcare professionals' experiences of working in the Saudi health sector under the newly proposed Vision 2030 and NTP 2020 interventions in the HRD sphere of healthcare. The Vision 2030 is a testimony to a revolutionary step taken by the Government to reform the Saudi healthcare sector and provide HRD opportunities.
\end{abstract}

\section{Keywords}

Healthcare, Human Resource Development, Saudization, Localisation, Vision 2030, NTP 2020

\section{Introduction}

Healthcare facilities in the Middle-Eastern region have significantly developed in recent times, particularly in the Kingdom of Saudi Arabia (KSA) [1]. A 2017 report by the Saudi Ministry of Health states that Saudi hospitals are now providing 2.2 beds for every 1000 people in the country [2]. Similarly, Almalki and FitzGerald [3] found that the Saudi government is committed to improving healthcare in the Saudi population and has prioritised the expansion of health- 
care services as a primary, secondary and tertiary level objective. Recently, however, a 2018 report from the Saudi Arabian Monetary Authority argues that the Saudi government needs to invest a hefty sum of money in social development health services in the region of SAR 146.5 billion, which accounts for $15 \%$ of the government's annual budget [4]. Despite the significant investments required to streamline healthcare in Saudi Arabia, the country has shown to be committed to making modern healthcare development a success. Having one of the highest ranked healthcare systems in the Middle-Eastern region $\left(26^{\text {th }}\right.$ as of 2020 behind Oman ranked $8^{\text {th }}$ according to the World Health Organisation (WHO)) is a testament of that commitment [5].

In spite of the these accomplishments in the Saudi healthcare system, a number of recent studies since the emergence of the Vision 2030 in 2016, argue that the healthcare sector still faces enormous challenges in the provision of improved healthcare services to rapidly growing population [6]-[11]. These studies claim that an improved healthcare system is expected to increase life expectancy, which presents the challenge of taking care of a growing elderly population. This places a significant burden on the existing infrastructure, which in turn calls for a large reserve of trained healthcare professionals. As a means to combat this scenario, Saudi Arabia has introduced a new strategic plan, Vision 2030, which presents various opportunities and potential public healthcare model for the health sector to adapt its strategic obligations and course for the future [12] [13] [14]. The limited training of healthcare professionals and strong dependence on foreign workers, as well as examining the Human Resource Development (HRD) initiatives to provide adequate learning and competence to a huge reserve of healthcare professionals, are important aspects for policymakers to consider and address. This paper contributes the documentation and evaluation of the steps suggested and undertaken by the Saudi Vision 2030 intervention and National Transformation Program (NTP) in the HRD sphere of healthcare.

\section{Theoretical Background}

Various models have been suggested to highlight the impact of healthcare Human Resource Development (HRD) initiatives on healthcare outcomes. Although the literature has covered these models, this review focuses on a number of key themes that emerge in the literature [3] [6] [12] [15] [16] [17]. Themes include the provision of better healthcare facilities to an increasing population, healthcare conditions, raising the standard of healthcare and affordability of healthcare, among others. While these themes are presented in different contexts, this paper mainly focuses on their application to the Saudi healthcare system and HRD context.

Despite relatively few models for public healthcare systems, there are various ways of how these unique models are applied. However, the unique nature of these models presents a challenge of raising the standards of healthcare while minimising the tax burden of healthcare on the general population. Bronfman 
[18] proposed one model to develop an effective level of private healthcare to include people who are able to afford it contrasted with public healthcare. Al-Hanawi and Khan [19] argues that this model of care can also be observed in KSA, in which widespread public healthcare is provided, though the private system, to some extent, is still relatively small and underutilised. However, the Vision 2030 strongly endorses the partnership of private and public sectors, but the acceptance of a declining public system in order for those who can afford private healthcare would be more willing to pay for treatment is an unacceptable solution [20]. This shows that the Vision's healthcare model heavily relies on productivity and efficiency. Similarly, Portela and Pronovost [21] states that a rational model of healthcare involves producing the best possible healthcare outcomes and measure potential gaps in healthcare intervention. The above models raise several questions as to what makes up an optimal outcome of healthcare, whether it is based on quality of life and longevity or is it based on curative or preventive medicine.

Alternatively, Mosca [16] mentioned concepts for improving productivity and efficient healthcare, such as interests within the healthcare system and removing monopolies. In addition, Smith [22] discusses a model of healthcare that has been adopted internationally and measures partial indicators that result in a health outcome. The author-inferred concepts, such as average cost of treating particular conditions and ailments, length of stay and labour hours. Nonetheless, it has been noted by Al-Nozha and Abdullah [15] that there is a significant increase in such conditions like chronic diseases, such as obesity, diabetes, hypertension and coronary heart diseases. This is supported by a 2018 report by the WHO, stating that KSA is the world's third ranking country for the prevalence of diabetes and obesity [23]. In the current health scenario, given the other issues stated such as population growth and the state of healthcare outcomes in KSA, there is a need to reform the health sector. Consequently, this paper analyses the impact of new strategic initiatives under the newly developed Vision 2030 intervention on the healthcare sector, which emphasises on healthcare Human Resource Development (HRD) initiatives.

\section{Methods}

This paper is based on a critical review of empirical data and information garnered from primary sources. With supported by semi-structured interviews. The unit of analysis is healthcare professionals operating in the Saudi health sector. Twenty interviews were conducted to complement our document analysis. Summary of the participants and their codes are summarised in Table 1. The rationale behind the below table is for a validity and ethical issues.

The paper attempts to evaluate the healthcare HRD sphere in KSA in order to explore the initiatives that intend on revitalising the Saudi health sector to facilitate the localisation or Saudization of the workforce employed in this sector. The evaluation of the documentation and interview data on healthcare HRD initiatives will add to the limited existing literature on the Saudi healthcare HRD 
Table 1. Summary of participants.

\begin{tabular}{|c|c|c|}
\hline No. & Participant & Code \\
\hline 1 & Nurse & N1 \\
\hline 2 & Doctor & D1 \\
\hline 3 & Medical Consultant & $\mathrm{MC1}$ \\
\hline 4 & Nurse & $\mathrm{N} 2$ \\
\hline 5 & Doctor & D2 \\
\hline 6 & Medical Consultant & MC2 \\
\hline 7 & Nurse & N3 \\
\hline 8 & Doctor & D3 \\
\hline 9 & Medical Consultant & MC3 \\
\hline 10 & Nurse & N4 \\
\hline 11 & Doctor & D4 \\
\hline 12 & Medical Consultant & MC4 \\
\hline 13 & Nurse & N5 \\
\hline 14 & Doctor & D5 \\
\hline 15 & Medical Consultant & MC5 \\
\hline 16 & Nurse & N6 \\
\hline 17 & Doctor & D6 \\
\hline 18 & Medical Consultant & MC6 \\
\hline 19 & Nurse & N7 \\
\hline 20 & Doctor & D7 \\
\hline
\end{tabular}

reform. As such, the paper can be a starting point of the existing healthcare HRD imperatives in the Vision 2030 context. The literature has found that the Vision 2030 present various challenges, in addition to opportunities for human resource policy development in the Saudi health sector. Therefore, the paper attempts to identify those challenges and opportunities in this regard, in addition to identifying the healthcare HRD, Vision 2030 and NTP Relationship, and the state of Saudization of the healthcare workforce.

\section{Results \& Discussion}

This section discusses and evaluates documentation from various reports and academic literature, which is supported by primary interview data of Saudi healthcare professionals who operate in the Saudi Arabian health system. The purpose of compiling these findings is to explore the initiatives presented by the 
healthcare HRD sphere in KSA that intend on revitalising the Saudi health sector to facilitate the Saudization of the workforce employed in this sector. Key topics covered include the challenges and opportunities of healthcare HRD in KSA, the healthcare HRD, Vision 2030 and NTP Relationship, and the Saudization of the healthcare workforce.

\subsection{Challenges \& Opportunities of Healthcare HRD}

The KSA is likely to continue spending heavily on its healthcare facilities given the country's projection that the elderly population will double over the next decade. This demonstrates that when life expectancy is raised, the requirement of workforce in the health sector during the next decade is likely to increase. This shows that Saudi Arabia needs a significant increase in the supply of the healthcare professionals in order to meet the increasing needs of its population that is both growing and ageing.

To meet the 2030 goal, a report by the McKinsey Global Institute [24] states that Saudi Arabia is required to employ a significant number of healthcare professionals, thus calling for an extra demand of healthcare professionals in the country. This is supported by one healthcare professional who stated (D1), "...fulfilling the objectives of Vision 2030 requires a huge number of Saudi nationals to be recruited in the healthcare sector." The Saudization aspect or the localisation of the workforce is highly important here to the Vision 2030. Presently, healthcare professionals ( 1 in 3 ) are actually Saudi. However, graduates of healthcare in KSA are insufficient in replacing retiring or leaving professionals, irrespective of filling in open job roles or not. With the increasing demand for healthcare from elderly Saudis requires KSA to fill a minimum of 100,000 healthcare related positions by the 2030 [24]. These findings from the McKinsey report support the projections made by some healthcare professionals in which one professional stated (D2), “...to meet the 100,000 minimum standard of active healthcare professionals by 2030, we would have to hire an average of 6000 7000 thousand new nurse per year." Yet, the overspecialisation of physicians in KSA has left a significant employment gap in family medical practitioners. This shows that only $5 \%$ of the KSA health workforce practice family medicine [24], which further adds to the healthcare employment dilemma in KSA, thus calling for detailed strategic objectives for transformational change in the country.

Concerning the challenges pertaining to transformational change in KSA, the MGI report encourages the participation of increased labour participation, particularly from the younger generation and women. It supports the development Saudi workers' skills through the provision of proper education and vocational training, in addition to enhancing flexibility of the labour market for Saudi workers, impeding growth of the public sector workforce, and raising the cost of foreign recruitment [24]. Incidentally, this highlights significant challenges as pointed out by the healthcare professionals. One healthcare worker stated (N1), “...one challenge refers to obtaining the available skilled workforce that has the potential 
to grow the KSA economy on a new level of productivity and efficiency." This supports the idea that meeting the required standard of Saudi workers in the healthcare sector can improve the country's infrastructure and support systems, while the population increases and ages. In other words, significant improvements are needed in the productivity and efficiency of the healthcare system, involving a combination of improved outputs relative to inputs, as well as more cost-effective uses of existing resources. A consequence of failing to meet this goal is that level of healthcare provision will deteriorate and creates an untenable health budget.

In order to improve and raise the standards of household income and absorb the demographic youth bulge, both women and men in Saudi Arabia will be required to be fully and equally involved in the workforce. Furthermore, the KSA will have to find ways to counteract the alarming discrepancy between individual skills and labour market requirements. The benefits and incentives involving work in the KSA are in conflict with having a truly productive labour force. For instance, workers in the public sector earn, on average, around $70 \%$ more than they earn, on average, those working in the private sector according to the MGI report [24]. Besides, the healthcare professionals (MC1) believe that “.... good number of employers opt to recruit expatriates lacking adequate skills as opposed to Saudi citizens who naturally demand double or triple the rate demanded by non-Saudis." This shows that Saudi healthcare professionals are not in full support of Saudization since they prefer skilled foreign labour over under skilled Saudis who are likely to demand extra wages.

Another challenge facing the KSA economy is the provision of better healthcare for creating an economic and controlling setting that encourages business through both transparency and unambiguity. However, the healthcare professionals are sceptical about creating such transparency as this would (MC3) "... warrant the need for building upon the progress achieved in KSA over the past decade regarding the fostering of competition and encourage foreign investors to develop the economy." Another healthcare professional argued that overcoming the economical barrier involves (D4) “...making multifaceted, controlling environments less complicated, less bureaucratic and easier to manage, through expediting procedures and developing a more productive and self-managed private-sector environment." This shows that healthcare HRD plays vital role to not only the health sector in KSA, but also the economy as well, thus warranting the need to explore the healthcare HRD, vision 2030 and NTP relationship.

\subsection{Healthcare HRD, Vision 2030 \& NTP Relationship}

Vision 2030 postulates that it will improve and employ the number of medical centres and hospitals in addition to improving the standards of services in the health sector, such as preventive and curative treatments. This further shows that the public sector's attention should be on prevention care and controlling infection, and urging people to prioritise primary care. The vision also aims to 
provide healthcare through public organisation as a means to raise its standards and prepare for the long-term advantages of privatisation. The NTP [25] report states that the vision plans to implement a strategic plan to improve the private medical insurance to enable individuals better access to medical services without long waiting periods until they are able to see a doctor. This supports the idea presented by one of the healthcare professionals (N4), stating “...if was given better training to improve treatment for chronic diseases like heart disease, diabetes and cancer, which all threaten people's health, then I can provide the level of care needed for my patients, but there is still a huge skills deficit in Saudi Arabia." In order to fill this skills deficit to provide better quality care and treatment to the Saudi citizens, the Vision 2030 aims to diversify the economy beyond the dependent oil reserves to reveal to promise the privatisation of some government services in KSA with the health sector being one of the prioritised sectors [25].

According to the NTP [25], the Vision 2030 also envisages to drive competitiveness and become the top 10 world's leading competitors on the Global Competitiveness Index (KSA is currently $25^{\text {th }}$ ) and increase the flow of Foreign Direct Investments from $3.8 \%$ of GDP to $5.7 \%$. It prescribes that by 2030 the share of the private sector will have risen from the existing $40 \%$ to $65 \%$ of GDP. The vision also aims to reduce the unemployment rate in KSA from $11.6 \%$ to $7 \%$ and to increase the representation of women in the workforce from $22 \%$ to $30 \%$. The NTP also 2020 introduced for the health sector, 15 strategic objectives and $16 \mathrm{KPIs}$ and KPTs, respectively.

These KPIs and KPTs act as a dashboard for evaluating the effectiveness of the NTP implementation. The relevant strategic priorities of the NTP that have a direct and indirect effect on the healthcare HRD are as follows:

1) Achieving adequate waiting times across all service delivery phases;

2) Enhancing healthcare sector productivity and effectiveness using information technology and digital transformation;

3) Improving health system governance with a view to improving accountability for quality and patient safety problems;

4) Improving principles of quality and safety and the skills of the service providers;

5) Improving the infrastructure, facilities management and healthcare safety standards;

6) Improving the quality of life and health care offered to patients outside hospitals;

7) Increasing national and international training and development;

8) Increasing the attractiveness of nursing and medical assistance personnel as a preferred career path;

9) Increasing the share of private sector spending by alternative methods of financing and service provision;

10) Speeding up the effective usage of available capital [25].

Emphasising and linking "affluence" diseases with an appropriate building of 
HRD capacity is also needed along with aggressive policy regulation, rather than simply increasing funding or the number of hospital beds, technology and medicine. An optimal change from the current one-third to a projected two-thirds ratio of Saudi-to-Expatriate workforce is likely to have taken place by 2030 via sustained policy interventions, which in turn can turn challenges into opportunities as predicted in the NTP 2020. In addition, there is scope for ensuring that potential investment in the healthcare sector meets the need for local HRD requirements with regard to job opportunities. In particular, for nurses, doctors and allied professionals, and disengages equally from expensive hospital consultant-level specialisation to specialist primary healthcare. This can be confirmed from a report by Almalki and Al-Hanawi [17] in which the authors state the essential need of launching models for public-private collaborations in the selection of potential resource sharing entities like human resources. The hospital utilisation rate needs to be dramatically increased from the current 53\%, especially in rural areas, with an emphasis on the growth of the local HRD initiative in the family medicine region employing local physicians, nurses and family medicine workers.

In this regard, the KSA faces three crucial challenges of healthcare reform, which can be turned into opportunities by making appropriate investments in this sector:

1) A demand for trained practitioners in both the clinical and health care sectors;

2) Having a health workforce that is not prepared to cope with the growing prevalence of non-communicable diseases;

3) Tackling the par financing and productivity present where the private sector should cover [26].

If KSA is to achieve the aforementioned objectives, a large number of Saudi nationals must be recruited in the sector. Now, one out of three healthcare practitioners is actually a Saudi citizen. For allied health professionals, e.g. technicians, assistants and therapists, a similar image may be observed but not as relevant.

If the KSA could make the Saudization rate, i.e. localising the workforce, it was projected that it would double for health specialists (e.g. two thirds), and by 2030 should generate roughly 400,000 posts. In addition, it is possible to build about 50,000 management and support posts too. Increasing the number of Saudi nationals who become health care practitioners needs to reverse a declining trend [26]. A healthcare professional confirms (D5) “...it is similar to making great efforts to improve the way well-talented Saudi youth view healthcare positions and to build a positive educational climate in faculties, universities and adequately equipped teaching hospitals." Currently, however, besides the restricted teaching capacity, a huge restriction lies in the lack of on-the-job training in public hospitals for medical assistants.

Today, medical practitioners are over-specialised with a significant shortage of 
family medical professionals. With the aging population of Saudi Arabia and the heavy burden of severe chronic diseases, the Kingdom is forced to transfer its medical workers to primary care. As well as the reallocation of health workers, one healthcare professional states (N5), “...innovative ideas are also needed in terms of the real challenges faced by medical professionals, such as flexible work hours and schedules dependent on shifts." Moreover, the traditional view of healthcare institutions, which are typically viewed as "hierarchical" and do not accept nurses for more advanced or specialised roles, would also need to be changed. The MGI report confirms that in addition to training and hiring, the private sector plays a major role in the growth of healthcare in the country [24]. Alternatively, the NTP 2020 aims to increase the attractiveness of nursing and medical support staff by offering a well-defined career path and increases the availability of trained Saudi nurses and support staff to 150 (per 100,000 population) out of the current 70.2 [26].

Currently, the private healthcare sector comprises up to $24 \%$ of hospital beds, which translates to roughly 17,622 out of 72,981 , and $32 \%$ of hospitals (roughly 158 out of 487). If the private healthcare sector were to establish itself, a clear strategy for the supply areas, which may be available for growth, would be required. Private sector providers, for example, may play a major role in the proper development of the provision of facilities in some areas such as long-term care, day surgery units, rehabilitation and secondary care hospitals distinguished by the restricted nature of the treatment rendered. Furthermore, the state could extend the privatization of particular areas such as the localisation of pharmaceutical production and health education. The NTP 2020 proposes that by 2020 , KSA would have achieved $40 \%$ of the current $20 \%$ share of pharmaceutical production. The Government has allocated some selected new facilities for opening in the coming years to private sector operators as a short-term target and will evaluate the efficacy of public and private sector partnership models together. Also ensuring cost neutrality and/or savings for government spending would be advantageous. From a law-enforced perspective, the state would have to tackle the obstacles to private sector involvement, including legal ownership requirements by Saudi doctors. Besides, the MGI report confirms that existing investment obstacles would need to be eliminated [24]. These goals and projections all aim to develop the Saudization of the healthcare workforce in KSA, but much work still needs to be done in order to bring this reality to fruition.

\subsection{Saudization of the Healthcare Workforce}

The rise in foreign workers in KSA and the scarcity of job opportunities for Saudi citizens have forced the Saudi government to take decisive steps to tackle the problems of widespread unemployment and to hire local people instead of expatriates. This recognition has sparked the coining of a new technological term "Saudization," meaning an innovative plan to train Saudi nationals properly to replace foreign or expatriate employees. The word was developed in the 1970s by 
the KSA government, but it was not until 1994 when the term was used in the economic sphere. Al-Asfour and Khan [27] confirms that the KSA government introduced the Saudization policy to mandate private sector companies with more than 20 workers to reduce the number of non-Saudis by $5 \%$ annually.

The private sector-focused Saudization program, known as the Nitaqat Program, was first introduced in Saudi Arabia in June 2011 and, subsequently, the level of Saudization in the private sector went from 10\% in 2011 to $13 \%$ by late 2012. Moreover, the private sector had responded passively to Saudization in the past, and the actual implementation of localisation was not successful until the late 1990s. In the healthcare sector, the foreign or expatriate staff make up about two-thirds of the doctors, nurses and pharmacists employed, according to the $\mathrm{MOH}$ annual report [2].

In contrast, the MGI report provides employment levels for all Saudi residents, an approximate growth in Saudization, i.e. the share of total private jobs, and the Saudi nationals' public sectors [26]. Currently there is a positive relationship between salaries and Saudization, where Saudi people take over highincome sectors and regulate low-income sectors through expatriate workers. It is anticipated that the potential impact of the government's efforts and policy changes will quickly accelerate the process of higher Saudization levels. Similarly, Saudi people are likely to start putting themselves in the posts currently filled by expatriate workers at the dominant low income currently earned by expatriate workers. The unemployment rate is growing significantly from the current levels, forcing the state to take action by restricting visas for expatriate workers using a fixed ratio, for example $50 \%$ for women and $10 \%$ for men. For female employment, in particular, it endorses that the female share of employment is likely to increase at a very high rate. There is a limit on the female employment projected for each sector depending on the type of sector and the traditional standards that prevail with regard to such work in KSA. Thus, based on the rate of Saudization, the need for the number of non-Saudi workers is estimated, assuming the present ratio of non-Saudi workers to the total non-Saudi population [26].

The purpose of launching the "Nitaqat" program was to replace the previous program for Saudization. Nitaqat (which translates into "zones" or "bands") sets Saudization targets for each private sector company with more than five employees. One healthcare professional confirms (MC4), “...the current Nitaqat program divides organisations into six categories Platinum, Green (high, medium, low), Yellow and Red, depending on their size and the percentage of the level of Saudization achieved." Another healthcare professional also adds (D5), "...categories Platinum and Green represent the highest proportions of Saudi nationals in their organisations, while Yellow and Red indicate the lowest proportions of Saudi nationals employed." Thus, it classifies them according to a colour scheme based on their performance: Red or Yellow refers to non-compliant companies, while compliant companies are referred to as Green, and finally 
outperforming organisations use Platinum. Nitaqat differed quite significantly from the previous programme. Firstly, the state could supervise the program effortlessly. Information and data on the number of Saudi national workers and expatriate workers recruited by a company were collected regularly and systematically using the state's integrated social insurance system and foreign visa records. The Nitaqat program was also implemented primarily to set attainable goals and targets. Nitaqat divided the companies into over 50 different business types. In addition, it classified them based on five different segments with fixed targets in each segment based on the level of Saudization already achieved by the companies in the segment in question. For instance, the MGI report confirms that if the number of employees in a company is between 6 and 49, the requirement for Saudization could be between $5 \%$ and $34 \%$ of the total workforce [26].

In contrast to previous efforts, policy makers have noted that "Nitaqat has real teeth". Those companies, which are referred to as red, are successfully stopped from growing because of the restrictions placed on them to reissue more visas for hiring expatriate workers. However, the Yellow companies impose fewer restrictions and Platinum companies are compensated for with swift and real-time access to expedited government services, including smooth visa processing and/or flexible grace periods after expiry. These results indicate a strong influence of Saudization in KSA through the country's efforts to reduce the number of expatriates in favour of hiring local Saudi talent as part of meeting the Vision 2030's expectations.

Recently, there has been a major shift in Saudi Arabia's policy direction, and the Government has taken a very rigorous initiative to balance its spending and fiscal deficit. The new Vision 2030 bears witness to the revolutionary steps taken by the government in all sectors. The healthcare sector also experiences a major shift in its approach and assumptions. The Government has chalked many plans, policies and benchmarks in the healthcare HRD initiatives to determine the effectiveness of all stakeholders. It has presented strategic goals, KPIs and KPTs, which give the healthcare, sector a very clear sense of direction.

The Government aims to generate SAR 4 billion from the private sector's use of its services in the next four years (2016-2020). It plans to increase private sector participation in healthcare expenditure by 10 per cent by 2020 ( 25 to 35 per cent). The government has taken a number of steps that will surely enhance Saudi workforce participation in the healthcare sector. The NPT 2020 clearly identifies areas for healthcare professionals for training and development, career planning and talent management. The Saudization of the workforce, which has long felt the need to counter Saudi youth's rising unemployment, will certainly find a response through these plans. Secondly, an optimal shift from the existing one-third to a projected two-thirds ratio of Saudi-to-Foreign workforce by 2030 through sustained policy approaches must be carefully adopted, thereby making challenges opportunities. There is considerable scope for the absorption of young Saudi trained boys and girls in the healthcare sector. 


\section{Conclusions}

The role of the private sector in establishing more medical, nursing and dental schools and other specialized educational institutions is both a challenge and an opportunity for the first movers in this sector. There will be a huge demand for healthcare professionals, and partnership between government and the private sector needs to accelerate this process by providing more learning and development facilities to counter healthcare professionals' growing demand. The role of the private sector in human resource training must therefore also be strengthened and redefined in the new context, in particular for long-term care, rehabilitation services, day surgery units and secondary care hospitals where the complexity of care delivery is limited.

Appropriate capacity building alongside aggressive policy regulation is needed, rather than increased funding or number of hospital beds, technology and medicine. It is also important to ensure that future investments in the health sector match the needs of local HRD healthcare. The launch of public-private partnership models in the selection of upcoming resource sharing institutions including human resources will be a real test. However, the policy direction set out in the new plan provides a synergy between all stakeholders and makes it easier to achieve the broader objective of economic diversification and empower the private sector to play a greater role. On the question of how credible and coherent this role is with the new initiative, only time will tell. Based on the findings and discussions of this paper, the following model has been developed to help understand the potential Healthcare HRD reform in Saudi Arabia (see Figure 1).

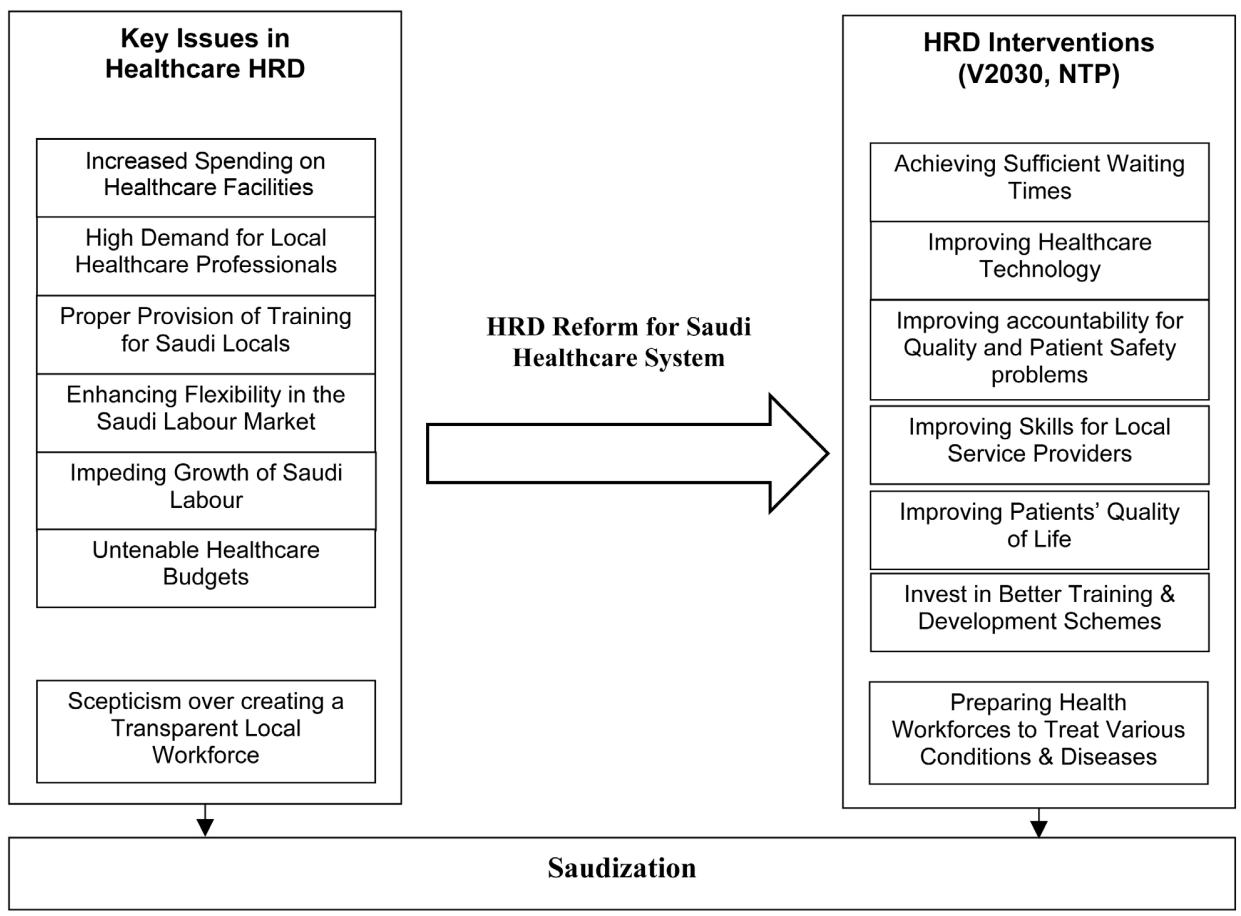

Figure 1. Model of potential healthcare HRD reform in Saudi Arabia. 


\section{Limitations of the Study}

The paper is a critical review of the Healthcare HRD reform adopted recently in Saudi Arabia, specifically Vision 2030 and NTP 2020, both of which were adopted in 2016 on the basis of the findings of the MGI report. Saudization (localisation) of the healthcare workforce and their learning and development are an important part of Saudi Arabia's government policy, and earlier research and insights on the Saudi healthcare reform have been mentioned in this regard. Data are limited to assess the effectiveness of these provisions adopted under the NPTs in the form of KPIs and KPTs, but attempts have been made to document and evaluate those provisions from the available resources as of today. This is a starting point for a future potential study that explores these provisions in more detail.

\section{Acknowledgements}

First, praise to Allah the almighty. Thank you to my family and friends who have supported me throughout my life and academic journey. Also, thank you to the research participants whose contributions made this paper possible.

\section{Conflicts of Interest}

The author declares no conflicts of interest regarding the publication of this paper.

\section{References}

[1] Walston, S., Al-Harbi, Y. and Al-Omar, B. (2008) The Changing Face of Healthcare in Saudi Arabia. Annals of Saudi Medicine, 28, 243-250.

https://doi.org/10.5144/0256-4947.2008.243

[2] Ministry of Health (2017) Annual Statistical Book. Ministry of Health, Riyadh.

[3] Almalki, M., FitzGerald, G. and Clark, M. (2011) Health Care System in Saudi Arabia: An Overview. EMHJ-Eastern Mediterranean Health Journal, 17, 784-793. https://doi.org/10.26719/2011.17.10.784

[4] Saudi Arabian Monetary Authority (2018) Fifty Fourth Annual Report. Saudi Arabian Monetary Authority, Riyadh.

[5] WHO (World Health Organization) (2020) World Health Report. World Health Organization, Geneva.

[6] Al-Hanawi, M.K. (2017) The Healthcare System in Saudi Arabia: How Can We Best Move Forward with Funding to Protect Equitable and Accessible Care for All. International Journal of Healthcare, 3, 78-94. https://doi.org/10.5430/ijh.v3n2p78

[7] Al-Hanawi, M.K., Alsharqi, O., Almazrou, S. and Vaidya, K. (2018) Healthcare Finance in the Kingdom of Saudi Arabia: A Qualitative Study of Householders' Attitudes. Applied Health Economics and Health Policy, 16, 55-64. https://doi.org/10.1007/s40258-017-0353-7

[8] Al-Hanawi, M.K., Vaidya, K., Alsharqi, O. and Onwujekwe, O. (2018) Investigating the Willingness to Pay for a Contributory National Health Insurance Scheme in Saudi Arabia: A Cross-Sectional Stated Preference Approach. Applied Health Economics and Health Policy, 16, 259-271. https://doi.org/10.1007/s40258-017-0366-2 
[9] Alharthi, H. (2018) Healthcare Predictive Analytics: An Overview with a Focus on Saudi Arabia. Journal of Infection and Public Health, 11, 749-756. https://doi.org/10.1016/j.jiph.2018.02.005

[10] Alatawi, A.D., Niessen, L.W. and Khan, J.A. (2020) Efficiency Evaluation of Public Hospitals in Saudi Arabia: An Application of Data Envelopment Analysis. BMJ Open, 10, Article ID: e031924. https://doi.org/10.1136/bmjopen-2019-031924

[11] Fadlallah, R., Bou-Karroum, L., El-Jardali, F., Hishi, L., Al-Akkawi, A., Tsolakian, I.G. et al. (2019) Quality, Safety and Performance Management in Primary Health Care: From Scoping Review to Research Priority Setting and Implementation Plan in the Eastern Mediterranean Region. BMJ Global Health, 4, Article ID: e001477. https://doi.org/10.1136/bmjgh-2019-001477

[12] Moshashai, D., Leber, A.M. and Savage, J.D. (2020) Saudi Arabia Plans for Its Economic Future: Vision 2030, the National Transformation Plan and Saudi fiscal Reform. British Journal of Middle Eastern Studies, 47, 381-401. https://doi.org/10.1080/13530194.2018.1500269

[13] Vision 2030 (2019) Saudi Vision 2030. Vol. 2019, KSA, Saudi Arabia, 39.

[14] Khan, M.K. (2018) Research, Innovation and Entrepreneurship in Saudi Arabia: Vision 2030. Taylor \& Francis Group, Abingdon.

[15] Al-Nozha, M.M., Abdullah, M., Arafah, M.R., Khalil, M.Z., Khan, N.B., Al-Mazrou, Y.Y., et al. (2007) Hypertension in Saudi Arabia. Saudi Medical Journal, 28, 77-84.

[16] Mosca, I. (2012) Evaluating Reforms in the Netherlands' Competitive Health Insurance System. Eurohealth, 18, 7-10.

[17] Almalki, A. and Al-Hanawi, M.K. (2018) Public Private Partnerships and Collaboration in the Health Sector in the Kingdom of Saudi Arabia: A Qualitative Study. Global Journal of Health Science, 10, 10-20. https://doi.org/10.5539/gjhs.v10n6p10

[18] Bronfman, J. (2011) Health Insurance Choice, Moral Hazard and Adverse Selection: A Study of the Chilean Case Using Panel Data. The Public Purpose, 1, 12.

[19] Al-Hanawi, M.K., Khan, S.A. and Al-Borie, H.M. (2019) Healthcare Human Resource Development in Saudi Arabia: Emerging Challenges and Opportunities-A Critical Review. Public Health Reviews, 40, Article No. 1. https://doi.org/10.1186/s40985-019-0112-4

[20] Grand, S. and Wolff, K. (2020) Assessing Saudi Vision 2030: A 2020 Review. Atlantic Council, Washington DC, 1-80.

[21] Portela, M.C., Pronovost, P.J., Woodcock, T., Carter, P. and Dixon-Woods, M. (2015) How to Study Improvement Interventions: A Brief Overview of Possible Study Types. BMJ Quality \& Safety, 24, 325-336. https://doi.org/10.1136/bmjqs-2014-003620

[22] Smith, P.C. (2012) What Is the Scope for Health System Efficiency Gains and How Can They Be Achieved? Eurohealth, 18, 3-7.

[23] World Health Organization (2018) Non-Communicable Diseases (NCD) Country Profiles. WHO Press, Geneva.

[24] McKinsey Global Institute (2015) Moving Saudi Arabia's Economy beyond Oil. McKinsey Global Institute, Amstelveen.

[25] NTP (National Transformation Program) (2018) Delivery Plan. National Transformation Program, Riyadh.

[26] McKinsey Global Institute (2015) Saudi Arabia beyond Oil: The Investment and Productivity Transformation.

https://www.mckinsey.com/ /media/McKinsey/Featured\%20Insights/Employment \%20and\%20Growth/Moving\%20Saudi\%20Arabias\%20economy\%20beyond\%20oil/ MGI\%20Saudi\%20Arabia_Executive\%20summary_December\%202015.pdf 
[27] Al-Asfour, A. and Khan, S.A. (2014) Workforce Localization in the Kingdom of Saudi Arabia: Issues and Challenges. Human Resource Development International, 17, 243-253. https://doi.org/10.1080/13678868.2013.836783 